\title{
Desarrollo de un sistema de almacenamiento y visualización de series de imágenes tomográficas para el Hospital Regional de Apizaco
}

\author{
Ricardo Ramos, María Guadalupe Medina, José Juan Hernández, Yesenia Nohemí \\ González, David Ibarra \\ Instituto Tecnológico de Apizaco, Tlaxcala, México. \\ ricramos1@icloud.com, lupitamb2@yahoo.com.mx, jjhmora@yahoo.com.mx, \\ yeseniaglez@hotmail.com, ibarra_david50@hotmail.com
}

\begin{abstract}
Currently problems caused by the high demand for imaging studies require the application of methods to improve quality and ensure that resources have optimal impact on the health and welfare of the population. SDSRI (Storage and Display System of Radiological Imaging) is a minimal system PACS (Picture Archiving Communication System), which was developed at the Technological Institute of Tlaxcala, and It will be implemented in the Regional Hospital of Tlaxcala "Emilio Sánchez Piedras". The system SDSRI allow the acquisition, processing, storage, retrieval and communication imaging hospital patients. The images and patient information structure will be obtained from the DICOM files decoding (Digital Imaging and Communications System) tomograph from the hospital, to be treated as JPEG images and patient database respectively. The decoding will be using the free library DCM4CHE Java based, therefore the system will be developed in this language. The system is intended to be used only as a client and allow full configuration to meet user needs, establishing a server where each office or authorized area will have access.
\end{abstract}

Keywords: PACS, DICOM, library, processing, database and picture.

\section{$1 \quad$ Introducción}

La radiología es la rama de la medicina que utiliza sustancias radioactivas, radiación electromagnética y ondas sonoras para crear imágenes del cuerpo, sus órganos y estructuras con fines de diagnóstico y tratamiento. Las imágenes pueden también mostrar la eficacia del funcionamiento del cuerpo, sus órganos internos y estructuras. 
En el área de radiología de un hospital, la parte de diagnóstico trabaja con imágenes radiológicas físicas (tomografías, radiografías, entre otros). El acceso a las imágenes radiológicas es en un archivo físico y su búsqueda es manual, lo que impide que su uso sea compartido.

En los últimos años, la tecnología ha avanzado con la construcción de sistemas y su uso no solo es en el área de radiología, sino en clínicas, hospitales pequeños, hospitales completos o en todas las áreas de un hospital. Aplicando el uso de estos sistemas beneficia tanto a la unidad clínica como al paciente, ya que el uso de las imágenes radiológicas es en un formato digital y su acceso es a través de un sistema que permite compartirlas y visualizarlas mediante consultas específicas lo que eficienta los procesos de diagnóstico y académicos.

PACS es un sistema de administración de imágenes que requiere datos pertinentes de otros sistemas de información médica para el funcionamiento eficaz. Entre estos sistemas, está el HIS (Hospital Information Systems), y el sistema RIS (Radiology Information System) que son los más importantes. Muchas funciones en el servidor PACS y servidor de archivos se basan en los datos extraídos de los dos HIS y RIS. [1]

Cuando se trabaja con imágenes digitales de este tipo (radiológicas) se tiene la necesidad de trabajar con un formato que sea leíble y además que pueda ser procesado por los equipos. DICOM (Digital Imaging and Communication in Medicine) es un estándar que fue creado en 1993 [1], el cual ayuda a que la información contenida en HIS pueda ser entendida y transferida tanto en un RIS como a un PACS con la finalidad de conjuntarla y poder trabajar con ella.

En este proyecto se elaboró un sistema que hace uso del estándar DICOM, el cual se desarrolló para la Jefatura de Enseñanza del Hospital Regional de Apizaco donde se tiene la necesidad de trabajar con un sistema que administre imágenes radiológicas, en el que personal autorizado pueda acceder y compartir las imágenes a través de un sistema de cómputo. El hospital cuenta con aparatos médicos, de los cuales se pueden obtener imágenes en forma digital, pero no se cuenta con algún sistema en el cual se puedan alojar dichas imágenes y el acceso a este material por parte de los médicos a menudo es tardado, sin embargo, con un sistema que administre sus imágenes se tendrá un uso compartido y de fácil acceso. Para fines didácticos la Jefatura de Enseñanza requiere de contar con un sistema que le presente al usuario, conjuntos de imágenes con algunas características en común.

\section{$2 \quad$ Metodología}

Las etapas del sistema SAVIR se formularon analizando algunas propuestas [2]-[4] y gran parte de las necesidades del hospital, lo que permitió usar un modelo de desarrollo de 
software basado en prototipos, con base a esto se plantearon las siguientes etapas para el desarrollo:

- Adquisición de las imágenes o series de imágenes radiológicas, obtenidas del servidor del tomógrafo del hospital.

- Importar las imágenes obtenidas del servidor del tomógrafo al servidor del sistema SAVIR.

- Tratamiento de los ficheros DICOM tal como decodificación y compresión.

- Decodificación de los ficheros para la obtención de los datos clínicos del paciente.

- Realización de una base de datos/imágenes.

- Consulta de datos e imágenes a través de un visualizador.

Para empezar con el desarrollo del sistema, se parte de un conjunto archivos tipo DICOM obtenidos del tomógrafo del hospital, por lo tanto se tendrán que decodificar para su almacenamiento en el servidor de SAVIR.

Cuando la información y las imágenes se encuentran en la base de datos, sólo queda que el médico de cada área pueda visualizar las imágenes y los datos ya decodificados, según sean sus privilegios.

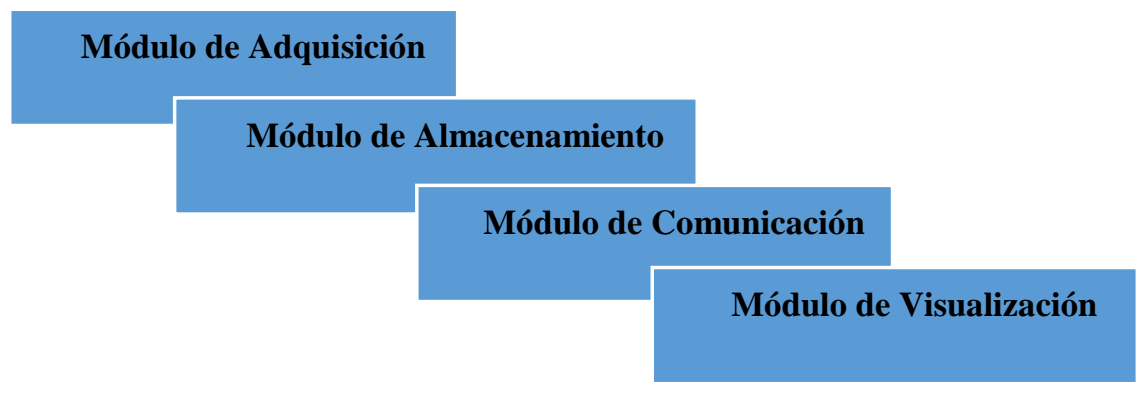

Fig. 1 Componentes de SAVIR.

El sistema SAVIR está formado por cuatro módulos: Adquisición, Comunicación, Almacenamiento y Visualización (Ver figura 1), relacionados entre sí, para cumplir con las funciones básicas de un PACS [1].

En la arquitectura de SAVIR (Ver figura 2), se aprecian los módulos mencionados. 


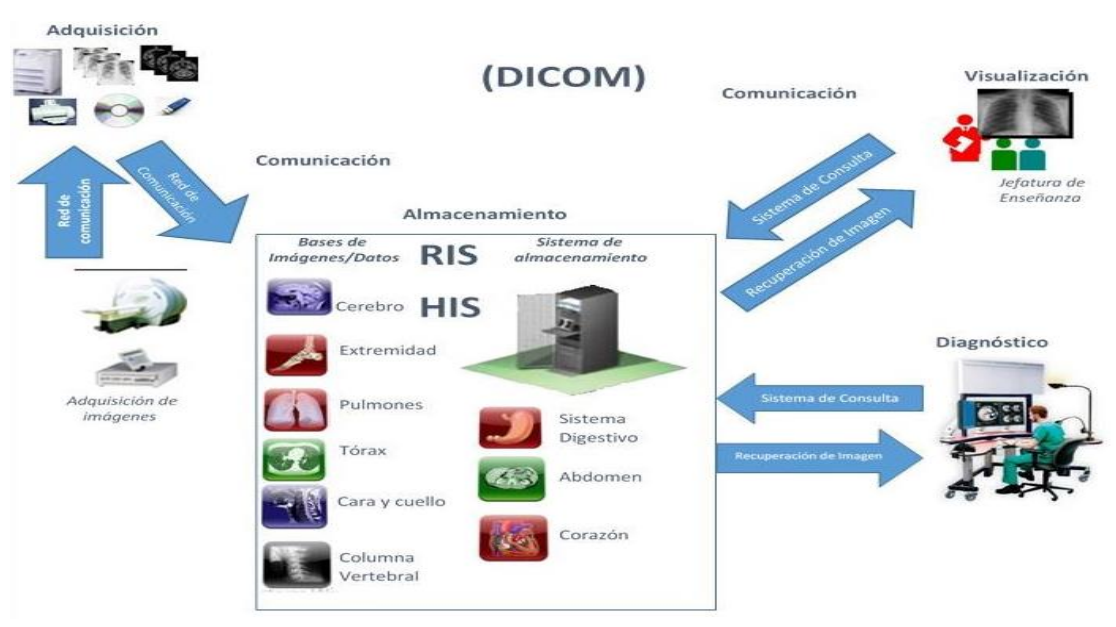

Fig. 2 Arquitectura del Sistema SAVIR.

\subsection{Adquisición}

Este módulo se encarga de la extracción de los ficheros DICOM, que se hace desde el servidor del tomógrafo, donde los ficheros son exportados a algún dispositivo de almacenamiento, que tenga la capacidad de guardar todos los estudios requeridos.

Los estudios tomográficos los extrae el encargado del área de tomografía, exportando solo los estudios que son solicitados por algún médico autorizado por el administrador.

\subsection{Almacenamiento}

Para poder importar todos los estudios recuperados al servidor de SAVIR, el administrador del sistema se ocupará de almacenar los ficheros. La persona que ocupa el papel de administrador contará con el privilegio de realizar esta función, todo esto por cuestiones de seguridad. Aquí, el usuario elegirá una ruta o directorio donde están ubicados los estudios, continuando con una decodificación de los ficheros, basándonos en una librería libre llamada DCM4CHE, que con base al análisis [5]-[6] y a los requerimientos del hospital se concluyó que era la mejor para la implementación.

Cuando se decodifican los archivos, primero se extraen algunos datos de la cabecera DICOM de los ficheros, ésta información se va almacenando en una base de datos dise- 
ñada en MySQL. Al mismo tiempo que se hace la decodificación para obtener la información, se hace otra con la finalidad de obtener la imagen del fichero en formato JPEG, almacenando en la base de datos solo la ubicación de esta imagen, para posteriormente procesarla.

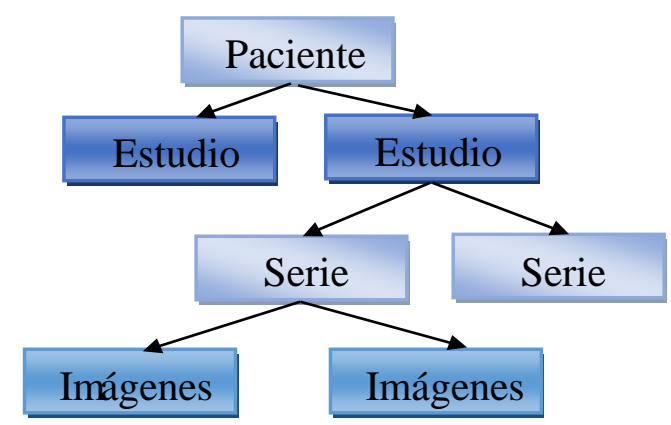

Fig. 3 Estructura de la información DICOM.

La información del paciente está estructurada por cuatro niveles: paciente, estudio, series e imágenes (Fig. 3), que son los que determinan las tablas que conforman la base de datos. La estructura está basada en la información que proporciona el formato DICOM. Un paciente es la parte fundamental, ya que indica que tipo de estudio se le realizó y ese estudio puede tener una o más series que están compuestas de imágenes.

\subsection{Comunicación}

Para la consulta de los estudios, SAVIR dará servicio a las distintas áreas o consultorios del hospital, esta comunicación estará regida bajo un protocolo de comunicación TCP/IP. En donde la comunicación será cliente/servidor y por cuestiones de seguridad los clientes no tendrán comunicación entre ellos.

La comunicación solo estará basada en hacer consultas desde alguna terminal con el sistema SAVIR, hacia el servidor del sistema.

\subsection{Visualización}

Cuando la visualización de un estudio es requerida, se realiza una búsqueda del estudio de interés. El usuario puede consultar estudios por medio de diferentes criterios tales como: nombre del paciente, descripción del estudio, fecha del estudio, médico solicitante, entre 
otros. Cuando se obtienen los resultados del o de los pacientes, se continua con la visualización de las series de los estudios.

Al haber elegido algún paciente para la visualización de su estudio, este estudio se muestra en un visualizador, en el que se cuenta con la opción de elegir entre las distintas series con que cuente tal estudio. El visualizador contiene herramientas básicas para el procesamiento de las imágenes [7-8].

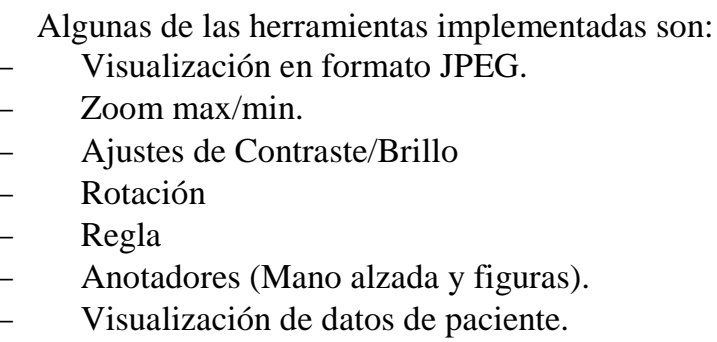

\section{Resultados}

Al implementar la librería DCM4CHE ya mencionada, se obtuvieron todos los metadatos de los ficheros DICOM, así como la obtención de las imágenes en formato JPEG con buena calidad ya que no se aprecia pérdida de información.

Con toda la información obtenida se elaboró una base de datos relacional (ver figura 4), que contiene toda la información requerida para poder realizar consultas.

Después de haber realizado la base de datos, se desarrolló en java el sistema para visualización de las tomografías.

En la entrada al sistema hay un combo que solo muestra los médicos dados de alta en el sistema y al administrador con su respectiva contraseña, con el objetivo que sólo tengan acceso a los estudios que ellos mismos solicitaron para sus pacientes, además que no tengan privilegios de acceso a todos los estudios y todas las funciones, ya que solo los tendrá el administrador.

Si el médico o administrador está dado de alta y tiene una contraseña asignada, podrá accesar al sistema (ver figura 5), con la opción de usar diferentes funciones. Si es administrador, tendrá los privilegios de: importar archivos, editar contraseñas, visualizar todos los estudios, ayuda, soporte y salir, es decir todas las funciones. Si se trata de un médico solo podrá tener acceso a soporte, ayuda, salir y consulta de estudios donde solo podrá visualizar los estudios que le pertenecen. 
Desarrollo de un sistema de almacenamiento y visualización de series de imágenes tomográficas ...

Cuando el médico o el administrador deseen buscar estudios, podrán hacerlo por nombre de paciente, descripción del estudio y fecha (ver figura 6). Se muestra el resultado de la búsqueda de paciente de un estudio específico.

Al tener todos los resultados de las consultas, se elige un estudio y se procede a mostrarlos en un visualizador (ver figura 7) el cual apoya su análisis con herramientas como: Zoom, rotar, brillo, nitidez, marcadores, notas, regla y mostrar la información del paciente.

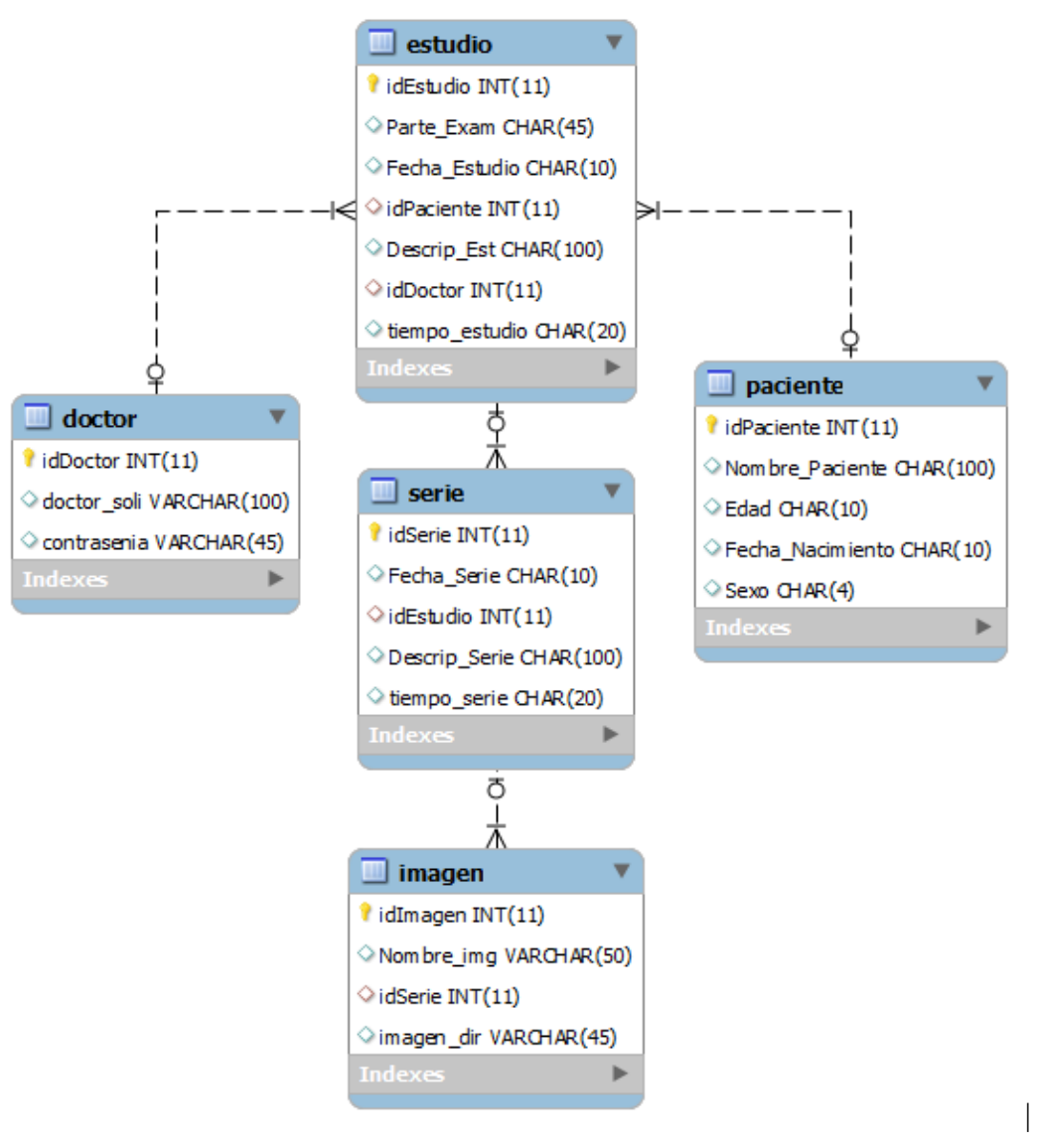

Fig. 4 Base de datos del sistema SAVIR. 


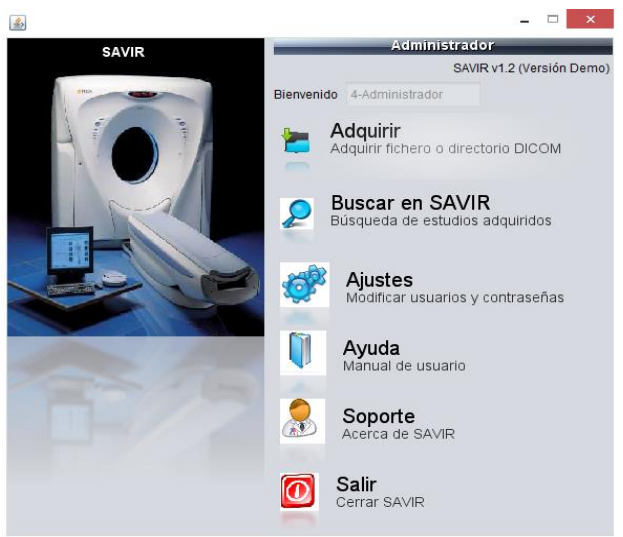

Fig. 5 Funciones de SAVIR .

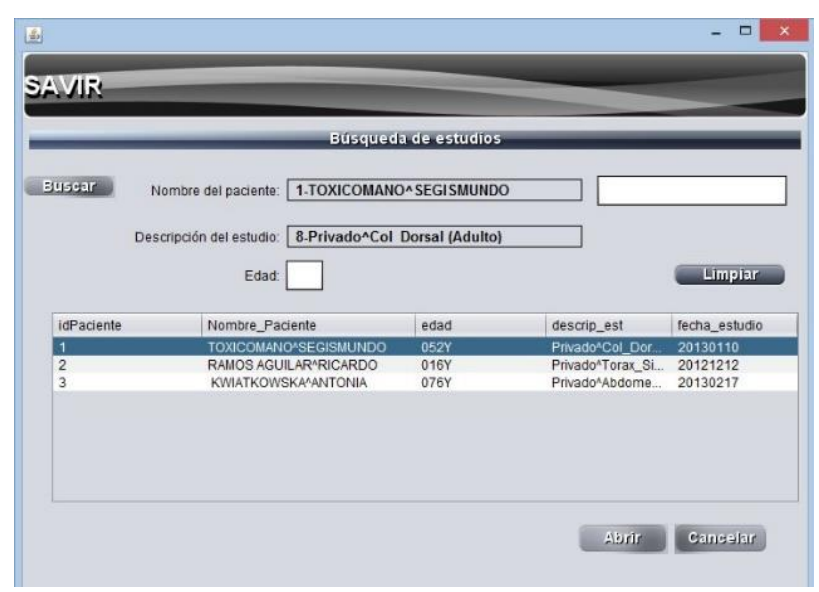

Fig. 6 Búsqueda de estudios

El usuario tendrá la opción de poder elegir en esta ventana alguna otra serie de imágenes disponible en el estudio.

Después de que el sistema se analizó en el Hospital Regional de Apizaco, se realizaron una serie de pruebas para lo que se diseñaron los siguientes cuestionarios, estos se enfocaron a medir: 1.- Satisfacción, 2.- Pruebas de contenido, 3.- Pruebas de almacenamiento, 
4.- Pruebas de consulta, 5.-Pruebas de visualización y 6.-Pruebas de seguridad. Las encuestas fueron aplicadas al encargado de sistemas del hospital y al encargado del administrador del sistema el Jefe de Enseñanza. Las respuestas de las encuestas arrojaron una promedio del $93.68 \%$ (ver figura 8) por parte del Administrador del sistema y el encargado de Sistemas del Hospital.

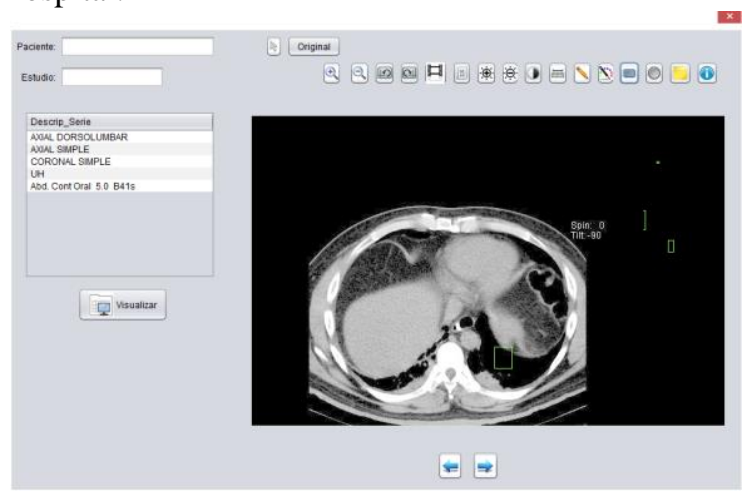

Fig. 7 Visualizador de estudios.

Estas pruebas muestran el desempeño del sistema, usando estudios de dos pacientes con sus respectivas series de imágenes, las imágenes e información hospitalaria fueron obtenidas al trabajar con aproximadamente 250 ficheros pertenecientes a los estudios ya mencionados, mostrando eficiencia en todas la pruebas, sin embargo el almacenamiento mostró deficiencia ya que no le fue posible almacenar una de cinco series de imágenes de un estudio, obteniendo una pérdida de información de aproximadamente 15 imágenes, relacionando este detalle a la librería usada.

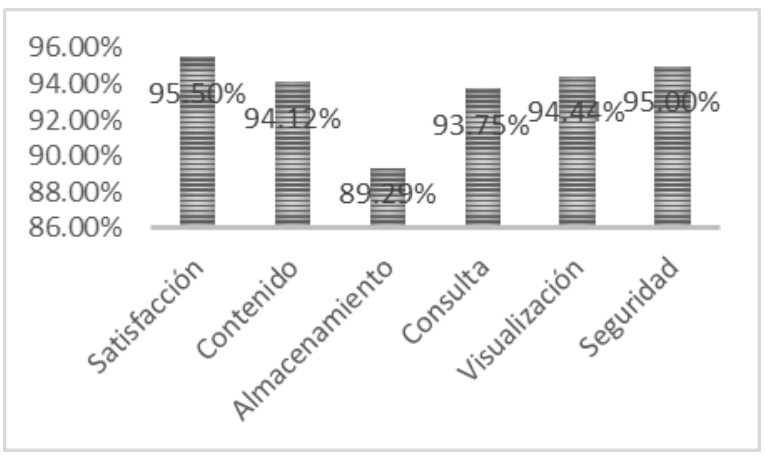

Fig. 8 Resultado general de pruebas. 


\section{Discusión}

Actualmente, la tomografía computarizada es un método muy común de diagnóstico y esto es porque permite visualizar distintas partes del cuerpo, que otros estudios no muestran con tanto detalle.

El hecho de que el hospital cuente con un sistema para poder administrar los estudios provenientes del tomógrafo del hospital, optimizará el acceso a las tomografías y a la información que éstas contienen. En la actualidad existen sistemas similares a SAVIR nombrados PACS, sin embargo el costo de instalar un sistema PACS en un hospital va más allá de la compra del equipo que se requiere. La diferencia entre los costos que cubre un hospital que cuenta con la tecnología PACS y uno con placas radiográficas, es que éstas últimas tienen un alto costo en el mercado.

Un PACS necesita de un HIS y un RIS para poder trabajar, esto regido bajo el estándar DICOM, por lo tanto debe contar con equipo médico con este estándar. El Hospital Regional de Apizaco cuenta con un solo equipo basado en este estándar (Tomógrafo computarizado), sin embargo, para darle solución a su necesidad de acceso rápido a información específica que contienen las tomografías, se propuso SAVIR.

El sistema que se desarrolló a diferencia de los otros sistemas PACS, trabaja muy independiente del servidor del tomógrafo por cuestiones de seguridad. Al no contar con un RIS dentro del Hospital, se creó una base de datos para poder exportar los datos del paciente. Las imágenes se exportan dentro del servidor de SAVIR en formato JPEG, con la finalidad de poder manipular las imágenes fácilmente y que el espacio que ocupen sea menor al ocupado por los ficheros DICOM, ya que un estudio promedio pesa entre 80 y 250 megabytes y al decodificar esa información sólo se ocupan entre 6 y 10 megabytes, lo que agiliza su transmisión y visualización. Al exportar todos los datos e imágenes nos proporciona rapidez, porque al accesar a los estudios cada vez que se requiera, no tendremos que estar decodificándolos del fichero DICOM, ya que estarán almacenados dentro de nuestro servidor, listos para ser utilizados.

Las pruebas realizadas al sistema se hicieron con base a diferentes tipos de cuestionarios como se mostró en los resultados. Se numeró a cada tipo respuesta de los cuestionarios, las cuales fueron cuatro y que al final se sumaron y se sacó un promedio ponderado para poder obtener esos porcentajes en una escala del $100 \%$.

Como se aprecia en la figura 8, se obtuvieron resultados de más de un $90 \%$ en general, esto nos indica que se desarrolló un buen sistema, sin embargo se obtuvo un resultado del $89 \%$ en la prueba de almacenamiento y esto fue a causa de la librería, ya que no fue capaz de reconocer un estudio el cual se intentó importar y el cual no tiene diferencia alguna de los otros con los cuales se realizaron pruebas. 


\section{Conclusión}

El estándar DICOM nos ofrece distintas maneras para la comunicación, almacenamiento y manejo de imágenes médicas. En el sistema SAVIR el estándar da una gran ventaja, ya que toda la información va almacenada en un solo fichero, lo que permite la movilidad de distintas series de imágenes radiológicas, su almacenamiento y visualización de estas en distintas áreas de un hospital. Sin embargo el estándar es bastante amplio y el procesamiento de estos archivos tiende a ser un poco complicado dependiendo del alcance que se desee, es decir; si se trabaja con transmisión, recepción, almacenamiento, seguridad, hace que el desarrollo de un sistema de este tipo sea más complejo. En el caso del sistema desarrollado sólo nos enfrentamos al entendimiento de la estructura y la decodificación del archivo, por lo tanto al haber obtenido información del paciente e imágenes del estudio, se trabajó directamente con una base de datos e imágenes sin necesidad de usar archivos DICOM.

La visualización de las imágenes decodificadas tienen una gran calidad, siendo de utilidad en el área de diagnóstico y/o enseñanza dentro de un hospital, y esto es porque las imágenes no muestran pérdidas, y el hecho de que el formato de salida sea JPEG nos da como opción el almacenamiento de muchos estudios.

Implementar SAVIR dentro de un hospital ofrecerá las siguientes ventajas y también presentará algunos requerimientos para su operación.

Ventajas:

Accesibilidad: Los estudios estarán disponibles cuando el médico lo requiera.

- Seguridad: La información será controlada por medios electrónicos (claves).

- $\quad$ Facilidad de almacenamiento.

- Economía: Se elimina la necesidad de procesamiento de placas impresas y los costos asociados (material y personal).

- Bases de datos: La calidad y la atención al paciente se incrementa significativamente al permitir búsquedas y visualización de sus estudios.

- Se puede hacer un seguimiento de los estudios de cada paciente, con la baja po sibilidad de pérdida de los estudios, ya que se encontrarán almacenados en el servidor de SAVIR.

- Visualización múltiple: Un estudio puede ser visto en diferentes lugares del hospital en forma simultánea.

- Ahorro de espacio físico: El espacio físico ocupado por tomografías es disminuido, debido a la utilización de un servidor.

- Procesamiento de imágenes: Las imágenes de un estudio pueden ser mejoradas realizando algún tipo de procedimiento, lo cual apoyará el diagnóstico. 
Requerimientos:

- Capacitación del personal: Para el manejo del sistema, es indispensable contar desde un inicio con capacitación del personal.

- Mantenimiento del sistema: Debido a las actualizaciones de DICOM, se necesitará dar mantenimiento a SAVIR.

Conforme a los resultados mostrados se concluye que el sistema desarrollado con el objetivo de almacenar y visualizar imágenes radiológicas basadas en el estándar DICOM, en este caso tomografías provenientes de un tomógrafo que maneja este estándar, el cual será usado en la jefatura de enseñanza del Hospital Regional de Apizaco "Lic. Emilio Sánchez Piedras" puede ser benéfico para el hospital, principalmente para el área de enseñanza, ya que los médicos internos y becarios que conforman el hospital se ocupan de analizar estudios que son de su interés en esta área.

\section{Agradecimientos}

Se agradece al Dr. Jorge Castro Pérez Director de la Jefatura de Enseñanza y al Departamento de Radiología del Hospital Regional de Apizaco SESA, por el apoyo, asesoría y estudios radiológicos que proporcionaron para realizar este proyecto en el marco del convenio de colaboración celebrado entre la Secretaria de Salud del estado de Tlaxcala y el Instituto Tecnológico de Apizaco.

\section{Referencias}

1. H. K. Huang, Pacs and Imaging Informatics Basic Principles and Applications, New Jersey, USA: John Wiley \& Sons, (2010)

2. Ronda, O. Ferrer, N. A. Alvarez, Imagis: Sistema para la transmisión de imágenes médicas multimodales, Memorias II Congreso Latinoamericano de Ingeniería Biomédica (Habana), Mayo (2001)

3. P. Suapang, S. Yimmun and A. Puditkanawat, Web-based Medical Image Archiving and Communication System for Teleimaging, 11 th International Conference on Control, Automation and Systems (Korea), Oct (2011)

4. M. Gerritsen, N. Putten, W. Dijk, W.Dassen, H. Spruijt, E. Spruijt, G. Uijen, R. Hainers, General DICOM Pacs Server for Echocardiography Images, Interuniversity Cardiology Institute of the Netherlands (Uthecht).

5. Vázquez A, Bohn S, Gessat M, Burgert O, Evaluation of Open Source DICOM Frameworks, BMBF-Innovation Center of Computer Assisted Surgery ICCAS, University of Leipzig. 
Desarrollo de un sistema de almacenamiento y visualización de series de imágenes tomográficas ...

6. Jason, G. Eric , H. Andrew, R. Alejandro dcm4che Architecture and Implementation, University of Illinois.

7. Piyamas S., Kobchai D. and Surapun Y., Medical Image Processing and Analysis for Nuclear Medicine Diagnosis, International Conference on Control, Automation and Systems (Korea), Oct (2010)

8. R. Kanda, J. Nantachai, J. Nuntapon, A. Supree, CT Image Management and Communication Services, Service Research and Innovation Institute Global Conference, (2012)

9. Digital Imaging and Communications in Medicine (DICOM) Part 6: Data Dictionary, National Electrical Manufacturers Association (Virginia), (2011) 